https://doi.org/10.48009/2_iis_2009_459-465

\title{
STUDENT PERCEPTIONS OF ELECTRONIC TEXTBOOKS
}

\author{
Matthew K. McGowan, Bradley University, mmcgowan@bradley.edu \\ Paul R. Stephens, Bradley University, prs@bradley.edu \\ Charles West, Bradley University, cwest @ bradley.edu
}

\begin{abstract}
Electronic books traditionally haven't been popular with the public but electronic textbooks have been starting to gain traction on college campuses. Textbook publishers and faculty have been experimenting with using them in the classroom with mixed success. Students seem less than enamored with electronic textbooks. This research uses a survey to examine student preferences regarding paper textbooks and electronic textbooks. We find that students overwhelmingly prefer paper textbooks. But, there are fundamental differences between students who prefer paper textbooks and those who prefer e-texts regarding the advantages of each format. We explore student perceptions of electronic textbooks, differences in student perceptions, and how these perceptions might impact the development and use of electronic textbooks in the classroom.
\end{abstract}

Keywords: Electronic Textbook, E-book, Student Learning, Technology Trend

\section{INTRODUCTION}

\section{Textbook Market}

There is a large market for textbooks, and textbooks represent a large expense for students. According to the Advisory Committee on Student Financial Assistance (ACFSA) [1], the average annual textbook expenditure for college students is $\$ 700$ to $\$ 1000$. Textbook expenses have been growing at a rate that far exceeds the consumer price index, and even outpaced the rate of increase for college tuition [1]. Electronic textbooks are often offered for lower prices than traditional textbooks [4, 9]. Publishers are starting to offer more electronic textbooks, but they claim to remain format-neutral [8]. Electronic books cost less to deliver so publishers can charge lower prices. Publishers may also be able to sell more copies, since electronic books usually cannot be resold. Students can benefit from lower overall book expenses. Electronic books remain a small but rapidly growing part of the book market $[4,7,8]$. It is unclear how that market will evolve as electronic textbooks evolve.

When the electronic textbook was first introduced to the marketplace, it was little more than a digitized copy of the paper textbook. Research at that time indicated that electronic textbooks (e-texts) provided no advantages to students in terms of the comprehension of the material [3]. Unfortunately, the electronic textbooks being offered today haven't varied much from their original form and tend to simply mimic paper based textbooks.

\section{A New Paradigm}

The vision for the electronic textbook represents a significant paradigm shift in how students read and learn subject matter. Beyond simply digitizing text, the e-text of the future allows students to perform searches within the text, includes interactive tables and figures, hyperlinks to related topics, case examples, and links to videos. The e-text also allows the student to cut and paste information from the book into other documents such as presentation slides. Some recent research indicates that a modern, more capable e-text can better help students learn complex material $[2,12]$. E-texts can be more easily kept up to date and improvements to the text can be incorporated more quickly. Therefore, students are more likely to get a textbook with the most current theory and application. Additionally, case examples and problems will better reflect the current environment in which students live and the way that instructors teach. E-texts could offer increased portability. Several textbooks can be carried on one laptop. E-texts can be used to promote active reading [6]. Electronic textbooks can allow students the ability to not only highlight text but also to undo highlighted text. This allows students to correct 
mistakes in highlighting more than they intended. It also permits a student to reflect on which portions of the text are important and modify the highlights. Electronic textbooks can enhance note taking. Students can add hyperlinked notes, modify them and delete them easily. E-texts can enable collaborative reading through the ability to share annotations among other readers of the text. E-texts can facilitate gathering data about how and when students read. As McFall [6] points out, "having an accurate measurement of student understanding would be an immense aid in tailoring classroom activities..." and "gaps in student knowledge are filled in through instruction and clarification only as necessary" due to the ability to track student text reading habits. Finally, the cost of an e-text is much less than the traditional textbook [9]. In a study by Shepperd et al.[9], the e-text cost 50-60\% less than the traditional paper textbook. This should also appeal to students who have seen significant increases in textbook prices during their short tenure at the academy.

\section{Student Perceptions}

For many students, reading an e-text versus a traditional paper text may seem daunting. Shepperd et al. [9] note a "parallel in writing and using computers." The authors suggest that there is a learning curve with today's generation but in terms of learning to effectively read e-texts that parallels the experience students had in transitioning their writing from paper to the computer. This seems to be supported by McFall [6] who found that students didn't utilize many of the e-text features designed to make them more active readers. The author explains this by stating, "students have developed reading habits, and changing those habits takes more time and attention than can be given in a single semester course" and that faculty can't use class time to discuss "reading strategies or ways to use the software."

Are e-texts simply perceived as inferior to the traditional textbook or are there actual disadvantages to electronic textbooks that spurn adoption by students? Previous research indicates that etextbooks do have disadvantages that need to be overcome. Students complain that reading from a computer text feels disjointed [12]. It is easier to experience eye strain when reading on a computer than with a traditional paper book $[5,9,11]$. E-texts require students to have a computer, preferably a laptop. But, even with the portability of a laptop, some authors claim that reading e-texts on a laptop is inconvenient and awkward [10]; if the computer fails, then the textbook is unavailable [9].

When it comes down to choice, research indicates that students overwhelmingly choose the traditional paper textbook over e-texts. Sixty-five to ninety percent of the students typically choose the paper textbook [9, 10, 11]. Vernon [11] asked graduate students about their preference after they used an electronic textbook in class. Seventy-one percent preferred a paper text. Shepperd et al. [9] focused on undergraduate students in an introductory psychology class, capturing data from students across different disciplines. Ninety percent of those students chose the paper textbook. Although the preferences for paper were high in both cases, we wondered whether the differences between these two studies $(71 \%$ versus $90 \%$ ) had something to do with the fact that one set of students was graduate students and one set of students was mainly freshmen and sophomore undergraduate students. So, one proposition that we explore is that the later it is in a student's career, the more likely the student prefers an electronic textbook.

In this study, we assess student perceptions of e-texts compared to the traditional paper textbook. It is the goal of this research to discover current student attitudes regarding e-texts. Previous research has found that students have a strong preference for paper textbooks. Recently, more and more students have been exposed to e-texts in their classes. We want to know if this experience has changed their attitudes concerning e-texts. Further, we want to know from the students' perspectives what they perceive to be problematic about using e-texts. Finally, we discuss whether the disadvantages of e-texts are real or simply a matter of perception brought about by the existing paradigm.

\section{METHOD}

A survey of 354 students was conducted in a variety of undergraduate and graduate courses in a college of business. Less that $1 \%$ of the students completing 
the survey were freshmen $(\mathrm{n}=2), 16 \%$ sophomores $(n=57), 50 \%$ juniors $(n=178), 20 \%$ seniors $(n=69)$ and $13 \%$ graduate students $(n=47)$ (Note: there was one non-respondent). Sixty percent of the respondents were female and $40 \%$ were male.

The anonymous survey consisted of seven questions and three demographic indicators (gender, age and year in school). The first question was used to learn whether students had been required to use an electronic textbook in a previous course. We did not ask about the e-texts they used or what features they had. At this point, we were simply exploring whether students had been exposed to electronic textbooks and what impact that exposure had on their perceptions of e-texts. The second question asked students about which type of book they would choose if given an option and the book were free of charge. Two questions dealt with the perceived advantages of traditional paper textbooks and e-texts. The two questions were identical except one asked about traditional textbooks and the other asked about the advantages of electronic textbooks (see table 1). Note that on table 1, the last response is open-ended. Very few of the students wrote anything in the blank and those that did offered very little insight. Therefore, this data was not included in our results.

Table 1. Perceived Advantages of paper textbooks and electronic textbooks

\begin{tabular}{|l|}
\hline What do you see as the advantages of a (paper / electronic) textbook? (check all that apply) \\
\hline Cost \\
\hline Ease of reading \\
\hline Weight \\
\hline Convenience \\
\hline Ability to highlight and take notes \\
\hline Ability to quickly find topics \\
\hline Can keep it as a reference book for future use \\
\hline Other (Please specify) \\
\hline
\end{tabular}

The demographic questions were used to assess whether students who preferred the electronic textbook differed from students who chose the paper text. The questions were also used to assess differences based on prior use of an e-text and reasons for choosing an e-text.

\section{RESULTS AND DISCUSSION}

\section{Book Type Preference}

Our findings indicate that students of all ages and experience levels overwhelmingly prefer paper textbooks to electronic textbooks. Eighty percent of the students in our survey would choose a paper textbook over an e-text (see Table 2). This is consistent with previous research $[5,9,10,11]$. In terms of our exploratory proposition that as students advance in their educational careers their preference for e-texts increases, we found that both undergraduate and graduate students prefer paper but that graduate students are more likely to prefer electronic textbooks (chisquare $=5.69, \mathrm{p}=.017$ ) . Graduate students had a greater preference for electronic books than undergraduates (34\% to $18 \%$ ). This was also reflected by age. Students who were 21 years of age or younger were less likely to prefer an electronic textbook than students who were older than 21 (chisquare=12.78, $\mathrm{p}<.01$ ). See tables 2 and 3 . Older students had a greater preference for electronic textbooks than younger students (30\% to 15\%). This is consistent with the study by Shepperd et al. [9]. This result warrants further study. It could be that more experienced students have developed study skills that would enable them to benefit more from the features of electronic books. Those students have likely had more research experience with other electronic materials (e.g., magazine articles, web sites) and may be able to transfer those skills to the use of electronic books. Some findings regarding the perceived advantages of paper texts and electronic texts may shed some light on this result. It also seems to demonstrate that although today's students have grown up with computers, they aren't being exposed to learning through computers like we might assume. Their experience prior to coming to the 
university still fits the traditional non-electronic learning environment of past generations.

Table 2. Preference and Level of Education

\begin{tabular}{|r|r|r|r|r|}
\multicolumn{4}{c}{ Education Level } \\
\cline { 2 - 5 } Preference & \multicolumn{2}{|c|}{ Undergraduate } & \multicolumn{2}{c|}{ Graduate } \\
\hline Paper & 249 & $82.2 \%$ & 31 & $66.0 \%$ \\
\hline Electronic & 54 & $17.8 \%$ & 16 & $34.0 \%$ \\
\hline \multirow{2}{*}{} & 303 & $100.0 \%$ & 47 & $100.0 \%$ \\
\cline { 2 - 5 }
\end{tabular}

Table 3. Preference and Age

\begin{tabular}{|r|r|r|r|r|}
\cline { 2 - 5 } \multicolumn{1}{c|}{ Preference } & \multicolumn{2}{|c|}{$18-21$} & \multicolumn{2}{|c|}{$22 \&>$} \\
\hline Paper & 204 & $84.65 \%$ & 76 & $69.72 \%$ \\
\hline Electronic & 37 & $15.35 \%$ & 33 & $30.28 \%$ \\
\hline & 241 & $100 \%$ & 109 & $100.00 \%$ \\
\cline { 2 - 5 }
\end{tabular}

Interestingly, we also found difference in preference based on gender. Both male and females prefer paper but male students are more likely to prefer an electronic textbook (chisquare=27.37, P<.01). See table 4. Compared to females, males tend to be more visual learners, so perhaps electronic textbooks provide a greater sense of visual learning. Or perhaps, it is a reflection of the overall gap that seems to exist between the genders in self-efficacy and interest in technology.

Table 4. Preference and Gender

\begin{tabular}{|r|r|r|r|r|}
\cline { 2 - 5 } Preference & \multicolumn{2}{|c|}{ Male } & \multicolumn{2}{c|}{ Female } \\
\hline Paper & 161 & $77.03 \%$ & 116 & $84.06 \%$ \\
\hline Electronic & 48 & $22.97 \%$ & 22 & $15.94 \%$ \\
\hline & 209 & $100 \%$ & 138 & $100.00 \%$ \\
\cline { 2 - 5 }
\end{tabular}

We also looked at prior use of an electronic textbook to determine if it had an impact on preference. We found that it did not (ChiSquare=.598, p=.44). See table 5. The percentage of students who preferred paper textbooks over electronic forms was nearly identical $(80 \%)$ for students regardless of whether they had previous experience with electronic textbooks. These figures seem to contradict the findings from Shepperd et al., who found students who used electronic textbooks were generally unwilling to use them in the future.

Table 5. Preference and Prior Use

\begin{tabular}{|r|r|r|r|r|}
\cline { 2 - 5 } \multicolumn{1}{c|}{ Preference } & \multicolumn{2}{|c|}{ No } & \multicolumn{2}{c|}{ Yes } \\
\hline Paper & 231 & $79.93 \%$ & 49 & $80.33 \%$ \\
\hline Electronic & 58 & $20.07 \%$ & 12 & $19.67 \%$ \\
\hline & 289 & $100 \%$ & 61 & $100.00 \%$ \\
\cline { 2 - 5 }
\end{tabular}

\section{Perceived Advantages and Disadvantages of E- texts}

Interestingly, there is little clear agreement amongst students on the advantages of paper textbooks and electronic textbooks. When we compared those students that prefer paper textbooks to those students that prefer electronic textbooks, clear statistical differences between the two groups emerged. There was statistical agreement between the groups on one item pertaining to paper textbooks (Can keep it as a reference book for future use) and one item pertaining to electronic textbooks (Cost). Students, in general, are looking for deep discounts when purchasing electronic textbooks. And, they are in agreement that this is a major advantage of e-texts. Obviously, one of the expectations of the paradigm shift in the eyes of the students is significant reductions in price. However, it should be noted from our findings that significant cost reductions alone are not going to drive students to use e-texts.

We also found that students generally agree that keeping an electronic textbook as a reference for future use is not an advantage of an electronic textbook. But, those students who prefer electronic textbooks are statistically more likely to see it as an advantage. See table 6. Given the ubiquity of computers and the ease of storing and accessing files from remote locations, one might expect the perception to be that the electronic text could always be handy for reference. In contrast, a paper textbook needs to be physically located near you when you might need it. In this regard, even if it is simply a digitized version of the paper text, an e-text would seem to be a more flexible reference source. Perhaps students are accustomed to gathering, organizing and storing such type of information for future use. 
Students do this all the time with music and pictures

but not with other types of digitized information.

Table 6. Percentage of students who perceive certain characteristics advantageous to either paper textbooks or electronic textbooks

\begin{tabular}{|c|c|c|c|}
\hline \multirow[b]{2}{*}{ Perceive as an advantage of paper text } & \multirow[b]{2}{*}{ All } & \multicolumn{2}{|c|}{ Preference } \\
\hline & & Paper & Electronic \\
\hline Cost & $4.2 \%$ & $2.8 \%$ & $10.0 \%$ \\
\hline Ease of reading & $73.6 \%$ & $82.1 \%$ & $41.4 \%$ \\
\hline Weight & $3.3 \%$ & $2.5 \%$ & $7.1 \%$ \\
\hline Convenience & $56.5 \%$ & $63.9 \%$ & $28.6 \%$ \\
\hline Ability to highlight and take notes & $36.5 \%$ & $42.2 \%$ & $15.7 \%$ \\
\hline Ability to quickly find topics & $75.1 \%$ & $78.9 \%$ & $62.9 \%$ \\
\hline Can keep it as a reference book for future use & $66.9 \%$ & $68.2 \%$ & $64.3 \%$ \\
\hline
\end{tabular}

Perceive as an advantage of electronic text

\begin{tabular}{|c|c|c|c|}
\hline Cost & $81.3 \%$ & $80.7 \%$ & $82.9 \%$ \\
\hline Ease of reading & $10.7 \%$ & $5.0 \%$ & $32.9 \%$ \\
\hline Weight & $63.3 \%$ & $59.3 \%$ & $78.6 \%$ \\
\hline Convenience & $38.4 \%$ & $31.8 \%$ & $64.2 \%$ \\
\hline Ability to highlight and take notes & $55.6 \%$ & $50.7 \%$ & $74.3 \%$ \\
\hline Ability to quickly find topics & $7.9 \%$ & $2.1 \%$ & $30.0 \%$ \\
\hline Can keep it as a reference book for future use & $17.2 \%$ & $14.6 \%$ & $25.7 \%$ \\
\hline
\end{tabular}

* Statistically significant difference between groups

There is general agreement between the two groups in terms of weight being an advantage of electronic textbooks but students who prefer e-texts are statistically more likely to believe this to be the case. A large majority in both groups generally agree that cost and weight are not an advantage of paper textbooks. Oddly, students who prefer electronic texts are statistically more likely to believe these to be advantages of a paper text.

There also is general agreement between the two groups in terms of their ability to quickly find topics when using a paper textbook, although, students who prefer paper texts are more likely to believe this to be the case ( $79 \%$ to $63 \%$ ). A majority of both groups generally agree that the ability to quickly find topics is not an advantage of electronic textbooks. But, the students that prefer electronic texts are significantly more likely to believe that this is an advantage of electronic textbooks ( $30 \%$ to $2 \%$ ). This result may appear counter-intuitive, since a word or phrase search could be performed with electronic books. However, an electronic search may find all instances of a word, whereas a well-constructed index may only list the most important entries related to a topic. A paperback book might also be easier to browse to find topics. It seems to be easier to get "lost" when reading an electronic text as you hyperlink from area to area and it is sometime problematic to get back to your point of departure. A paper textbook, on the other hand, is linear and it is easy to move from one location to another and back again.

In terms of convenience, there is a significant split in perception between the two groups. As one might expect, students who prefer paper texts are much more likely to state that a paper textbook offers convenience and the electronic textbook does not. The perceptions are flipped for the students who prefer electronic textbooks. Two thirds of the students in each group believe that their preference is the more convenient choice. Among students who 
indicated a preference for paper textbooks, nearly $64 \%$ indicated that paper textbooks were more convenient. Among students who indicated a preference for electronic textbooks, $64 \%$ indicated that the electronic textbook was convenient. Similarly, only $29 \%$ of paper preferring students thought electronic textbooks were convenient and only $32 \%$ of students with electronic format preference indicated that paper textbooks were convenient. These are remarkable contrasts among the two groups. Perhaps the difference in perception might be driven by the computer carrying behavior of the student. Students who routinely carry and use their computers wherever they go would be more likely to cite electronic books as more convenient that paper texts.

Forty-two percent of the paper preferring students indicated that the ability to highlight and take notes was an advantage of paper books, while a slightly higher percentage of electronic textbook preferring students agreed $(51 \%)$. There was a sharp difference in the percentage of paper preferring students who thought the ability to highlight and take notes was an advantage of electronic textbooks (16\%) while $74 \%$ of electronic textbook preferring students perceived that as an advantage of the electronic textbook. This might indicate that many students are unaware of the features of electronic textbooks or have been exposed to e-texts without such features. Alternatively, this may also suggest that the ability to highlight and take notes is more important to this group of students. If these are more experienced students, as suggested by previous results, perhaps they are using a different set of study skills in using textbooks. The promotion of active reading is one of the advantages that supporters of the modern e-text cite as driving the transition from the paper paradigm to the electronic paradigm. Active readers do more than just read the text, they annotate the text through highlighting and taking notes. From our analysis, it appears that students who prefer electronic textbooks are less likely to perceive these functions as advantageous to paper textbooks but three quarters of these same students perceive electronic textbooks as offering advantages when it comes to highlighting and taking notes.
When it comes to the ease of reading, both groups generally agree that this is not an advantage of electronic texts. But, those students who prefer etexts are statistically more likely to cite this as an advantage of e-texts. The groups are really split on ease of reading when it comes to paper textbooks. Eighty two percent of the students who prefer paper texts perceive ease of reading as an advantage of the paper text. Whereas, only $41 \%$ of the students who prefer e-texts believe that the ease of reading is an advantage of paper textbooks. Ease of reading is a fairly loose construct that might be open to different interpretations. Some people might interpret it as comfort, or a strain on the eyes or others may see it more as an aspect of convenience. For example, if I am a student that is always at my computer, then it isn't as easy to have a paper book open to read while also working on my computer. On the other hand, it is easy to have an electronic book open while I do other things on the computer. Hence, I perceive it as easier to read.

\section{FUTURE RESEARCH}

Future researchers should begin by examining how textbooks are used in student learning. If one can discover what features of books are useful, this information could be used in defining the new paradigm of the electronic textbook and planning how to structure it. Researchers need to start looking at different formats of electronic textbooks to understand what features and capabilities will enhance the student's experience with electronic texts. They also need to explore strategies that will allow students to learn how to optimally use electronic textbooks.

To better understand student perceptions, the loose constructs that we use for the advantages need to be better defined and interpreted. Interviews with students from both groups (those who prefer e-texts and those who prefer paper textbooks) will allow us to better understand students' definitions of and perceptions of the advantages of paper and electronic textbooks. Further research in this area will allow us to connect the voice of the student to the design of the electronic textbook of the future. 


\section{REFERENCES}

1. Advisory Committee on Student Financial Assistance (ACFSA). (2007) Turn the page: Making college textbooks more affordable, Washington, D. D., http://www.ed.gov/about/bdscomm/list/acfsa/tur nthepage.pdf, accessed March 29, 2009.

2. Appleton, L. (2005) Using electronic textbooks: promoting, placing and embedding. The Electronic Library, 23(1), 54-63.

3. Aust, R., Kelley, M.J., \& Roby, W. (1993) The use of hyper-reference and conventional dictionaries. Educational Technology Research and Development, 41(4), 63-73.

4. Hannon, Charles. (2008) E-texts in the classroom. Educause Quarterly, (1), 12-13.

5. Levine-Clark, Michael. (2006) Electronic book usage: A survey at the University of Denver. Libraries and the Academy, 6(3), 285-299.

6. McFall, R. (2005) Electronic textbooks that transform how textbooks are used. The Electronic Library, 23(1), 72-81.

7. Nelson, Mark R. (2008) E-books in higher education: Nearing the end of the era of hype? Educause Review, (March/April), 40-56. (Reprinted from Educause Center for Applied Research Bulletin, vol. 2008(1).

8. Rampell, Catherine. (2008) Free Textbooks: An online company tries a controversial publishing model. Chronicle of Higher Education, 54(34).

9. Shepperd, J.A., Grace, J.L., \& Koch, E.J. (2008) Evaluating the electronic textbook: Is it time to dispense with the paper text? Teaching of Psychology, 35, 2-5.

10. Walton, E.W. (2007) From the ACRL $13^{\text {th }}$ national conference: E-Book use versus users' perspective. College and Undergraduate Libraries, 14(4), 19-35.

11. Vernon, R.F. (2006) Paper or pixels? An inquiry into how students adapt to online textbooks. Journal of Social Work Education, 42(2), 417427.

12. Young, J.R. (2001, May 18) A university that reveres tradition experiments with e-books. The Chronicle of Higher Education, p. A39. 